\title{
Non-Contact Velocity Measurement of Japanese Cedar Columns Using Air-Coupled Ultrasonics
}

\author{
Masumi Hasegawa ${ }^{1 *}$, Misaki Mori², Junji Matsumura1 \\ ${ }^{1}$ Department of Agro-Environmental Science, Faculty of Agriculture, Kyushu University, Fukuoka, Japan \\ ${ }^{2}$ Graduate School of Bioresource and Bioenvironmental Science, Kyushu University, Fukuoka, Japan \\ Email: "kmgtmsm@agr.kyushu-u.ac.jp
}

Received 1 December 2015; accepted 30 January 2016; published 5 February 2016

Copyright (C) 2016 by authors and Scientific Research Publishing Inc.

This work is licensed under the Creative Commons Attribution International License (CC BY).

http://creativecommons.org/licenses/by/4.0/

(c) (i) Open Access

\begin{abstract}
The ultrasonic wave velocities of Japanese cedar columns were measured using a non-contact method. An air-coupled ultrasonic wave was propagated through the axial and lateral directions of wood. The velocities in the axial direction $\left(V_{L}\right)$ showed the minimum values around the pith. The averaged $V_{\mathrm{L}}$ increased from $3600 \mathrm{~m} / \mathrm{s}$ towards the outside of measurement area and attained the maximum values $(=4010 \mathrm{~m} / \mathrm{s})$. The velocities in the lateral direction $\left(V_{R T}\right)$ showed no tendency among measurement points. The averaged $V_{R T}$ was $1450 \mathrm{~m} / \mathrm{s}$. The velocities obtained using the non-contact method showed a significant positive relationship with those obtained using the contact method. The averaged ratio of $V_{L}$ to $V_{R T}$ was measured to be approximately 2.2 to 2.8 . These ratios were in agreement with those from a contact method. These findings suggest that it is possible to measure the velocity in Japanese cedar columns with the non-contact method by using aircoupled ultrasonics.
\end{abstract}

\section{Keywords}

Air-Coupled Ultrasonics, Velocity, Non-Contact Method, Nodestructive Evaluation, Japanese Cedar

\section{Introduction}

Japanese cedar is a popular tree cultivated in Japan. The distribution area of Japanese cedar is the largest among planted forestry species, accounting for $26 \%$ of the country's total. In addition, $64 \%$ of roundwood production of Japanese cedar is used for sawnwood. The Plan to Create Dynamism through Agriculture, Forestry, and Fishe-

\footnotetext{
${ }^{*}$ Corresponding author.
}

How to cite this paper: Hasegawa, M., Mori, M. and Matsumura, J. (2016) Non-Contact Velocity Measurement of Japanese Cedar Columns Using Air-Coupled Ultrasonics. World Journal of Engineering and Technology, 4, 45-50. 
ries and Local Communities was enacted in 2013. Forestry will become a growth industry through the creation of new wood demand and the building of a stable and efficient supply scheme [1]. As a result, demand for Japanese cedar as an engineering wood is expected to increase significantly in the future. Therefore, it is important to understand the usage of ultrasonic techniques to perform nondestructive evaluation of Japanese cedar. Hasegawa et al. demonstrated that the ultrasonic wave velocities along the longitudinal direction of Japanese cedar exhibited strong correlations with the tracheid length and microfibril angle with a significant level of $p<0.01$ [2]. In addition, Mori et al. evaluated the surviving strength of bending of Japanese cedar damaged by termite [3]. It was possible to evaluate the surviving strength using the ultrasonic velocity in the longitudinal direction. Hasegawa et al. investigated the within-tree variation of the acoustoelastic behaviors in Japanese cedar to clarify the possibility of nondestructive stress measurement [4].

Recently, air-coupled ultrasonic waves have been studied for use in the quality control of sawing timber and the maintenance of posts and beams in a wooden construction [5]-[9]. This technique makes it possible to evaluate the current state of the wood without contacting the wood. Vun et al. evaluated the relationships between moisture content and ultrasonic wave velocity in red pine [5], while Dahmena et al. measured the elastic constants of an olive wood plate [6]. To the best of our knowledge, there is no report for evaluating Japanese cedar by using air-coupled ultrasonics.

In this study, we tried to measure the ultrasonic wave velocity in Japanese cedar columns with a non-contact method. The air-coupled ultrasonic wave was propagated through the axial and lateral directions in wood. The validity of the ultrasonic wave velocities using the non-contact method was experimentally investigated. In addition, the velocities obtained using the non-contact method were compared with those obtained using the contact method.

\section{Materials and Methods}

\subsection{Materials}

Japanese cedar (Cryptomeria japonica D. Don) was used as the test material. Test specimen dimensions were $100 \mathrm{~mm}$ (longitudinal) $\times 100 \mathrm{~mm}$ (radial) $\times 100 \mathrm{~mm}$ (tangential). Numbers of test specimens were 3 pieces (S1, S2, S3). The air-dried density and moisture content show in Table 1.

\subsection{Ultrasonic Measurement}

An air-coupled ultrasonic wave was propagated through air and specimens of wood, as shown in Figure 1. Ultrasonic wave velocities were measured by using a pulser-receiver (JPN-10CKN, Japan probe Co. Ltd., Japan), a preamplifier, and monolithic composite transducers of type $14 \times 20 \mathrm{~mm}$ with a natural frequency of $200 \mathrm{kHz}$ (Japan probe Co. Ltd., Japan). The propagation directions of the ultrasonic wave corresponded to the axial (longitudinal) and lateral (radial or tangential) directions in wood. Ultrasonic velocity was measured at nine points on the surface of cross and tangential sections, respectively (Figure 2). The room temperature $(t)$ and velocity measurement were recorded at the same time. The ultrasonic velocity $(V)$ was calculated using Equations (1) and (2).

$$
\begin{gathered}
V=L /\left(T-\left(T_{a}-L / V_{a}\right)\right) \\
V_{a}=331.5+0.61 t
\end{gathered}
$$

where $L$ is the propagation distance of wood, $T$ is the propagation time with a wood sample, $T_{a}$ is the propagation time without a wood sample, and $V_{a}$ is the velocity in air.

Table 1. Density and moisture content of test specimens.

\begin{tabular}{ccc}
\hline Specimens & Density $\left(\mathrm{kg} / \mathrm{m}^{3}\right)$ & Moisture content (\%) \\
\hline S1 & 333 & 9.2 \\
S2 & 323 & 9.2 \\
S3 & 336 & 9.1 \\
\hline
\end{tabular}




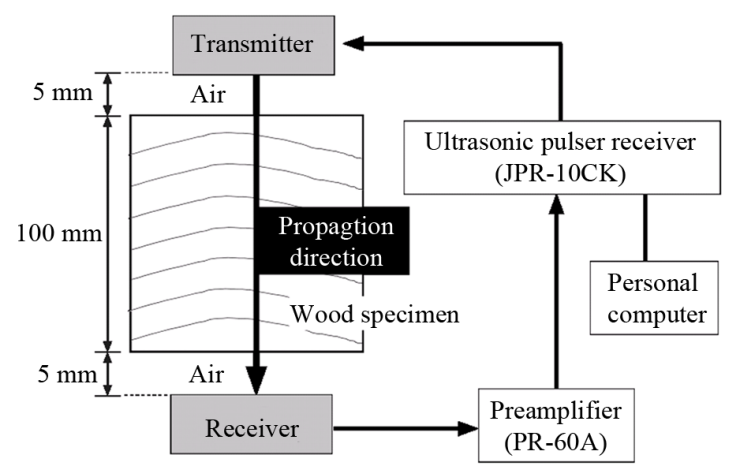

Figure 1. Diagram of ultrasonic wave measurement.

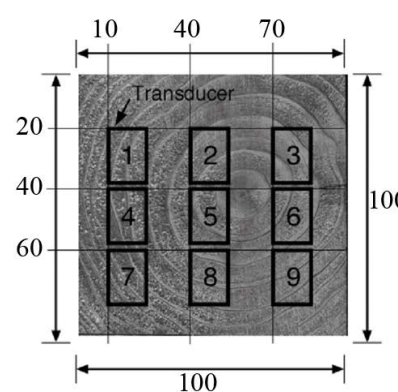

(a) Axial direction

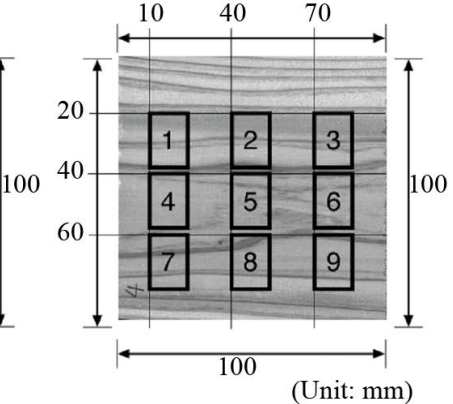

(b) Lateral direction

Figure 2. Measurement positions of ultrasonic wave velocities.

In addition, the ultrasonic wave velocities were measured using the contact method. The measurement equipments were the same as those used in the non-contact method. The ultrasonic velocity $\left(V_{c}\right)$ was calculated using Equation (3).

$$
V_{c}=L /\left(T_{c}-T_{0}\right)
$$

where $L$ is the propagation distance of wood, $T_{c}$ is the propagation time with a wood sample, and $T_{0}$ is the propagation time without a wood sample.

\section{Results and Discussion}

\subsection{Receiving Waveform for Air-Coupled Ultrasonics}

Figure 3 shows the receiving waveform in air at $110 \mathrm{~mm}$ distance between transducers. The propagation time was determined using a zero-crossing method. The propagation time showed about $330 \mu$ s. Figure 4 shows the examples of receiving waveforms in axial and lateral directions of wood. The propagation time in wood is smaller than that in air, because an ultrasonic velocity in wood is faster than that in air. The averaged propagation time in axial and lateral directions was about $60 \mu \mathrm{s}$ and $100 \mu \mathrm{s}$, respectively. The propagation time was ranked in the ascending order of lateral and axial directions. These propagation times were substituted for Equation (1) in order to calculate the velocities. As shown in Figure 3, some small signals that were observed before the receiving waveform are used to determine the propagation time. The small signals may have some important information for ultrasonic propagation characteristics. Further research is required to study these small signals.

\subsection{Ultrasonic Wave Velocities in the Axial and Lateral Directions}

Table 2 shows the ultrasonic wave velocities in the axial and lateral directions for three test specimens (S1, S2, S3). The average values of velocity in the axial direction $\left(V_{L}\right)$ were $3964 \mathrm{~m} / \mathrm{s}, 3515 \mathrm{~m} / \mathrm{s}$, and $3468 \mathrm{~m} / \mathrm{s}$, respectively. Figure 5 shows the values of ultrasonic wave velocity each position in the axial and lateral directions. The minimum values for $V_{L}$ show $3597 \mathrm{~m} / \mathrm{s}, 3234 \mathrm{~m} / \mathrm{s}$, and $2733 \mathrm{~m} / \mathrm{s}$, respectively. Their values existed around 


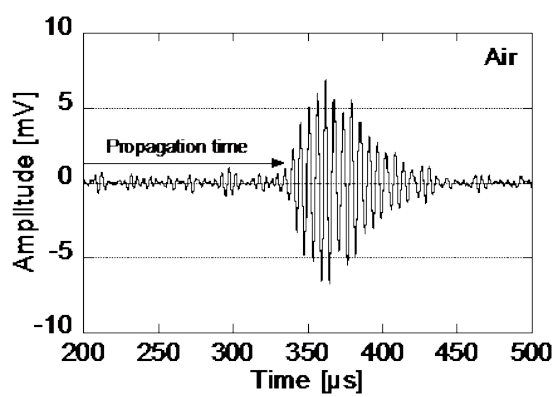

Figure 3. Waveform of ultrasonic wave in the air at $110 \mathrm{~mm}$ distance.
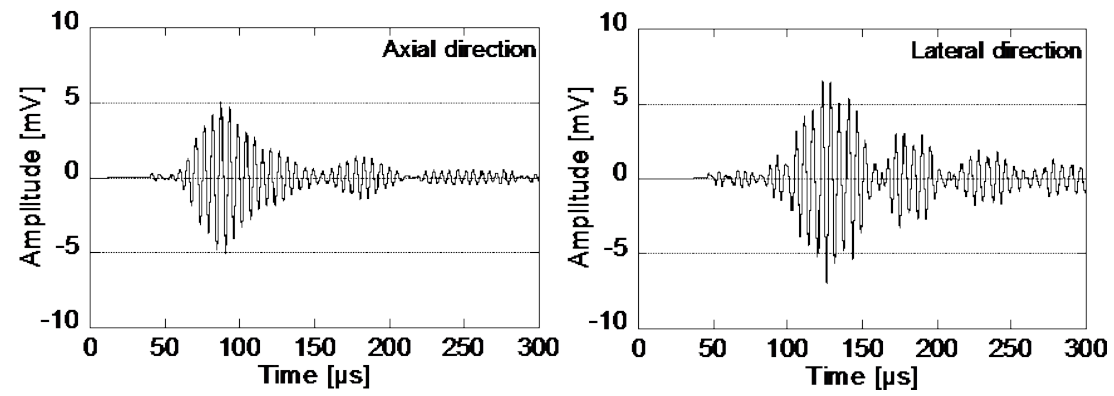

Figure 4. Waveforms of ultrasonic wave in the axial and lateral directions of wood specimens.

Table 2. Ultrasonic wave velocities in axial and lateral directions.

\begin{tabular}{|c|c|c|c|c|c|}
\hline \multirow{2}{*}{ Specimens } & $V_{L}$ & $V_{R T}$ & \multirow{2}{*}{$V_{L} / V_{R T}$} & Frequency & \multirow{2}{*}{ Method } \\
\hline & \multicolumn{2}{|c|}{$(\mathrm{m} / \mathrm{s})$} & & $(\mathrm{kHz})$ & \\
\hline S1 & $3964 \pm 283$ & $1412 \pm 155$ & 2.8 & \multirow{3}{*}{200} & \multirow{3}{*}{ Non-contact } \\
\hline S2 & $3515 \pm 180$ & $1606 \pm 92$ & 2.2 & & \\
\hline S3 & $3468 \pm 335$ & $1331 \pm 235$ & 2.6 & & \\
\hline S1 & $4118 \pm 240$ & $1664 \pm 147$ & 2.5 & \multirow{3}{*}{200} & \multirow{3}{*}{ Contact } \\
\hline S2 & $4164 \pm 253$ & $1677 \pm 84$ & 2.5 & & \\
\hline S3 & $4096 \pm 410$ & $1700 \pm 130$ & 2.4 & & \\
\hline Japanese cedar ${ }^{\mathrm{a}}$ & $4310 \pm 339$ & $\begin{array}{c}1863 \pm 9.0^{\mathrm{c}} \\
1388 \pm 15.1^{\mathrm{d}}\end{array}$ & $\begin{array}{l}2.3 \\
3.1\end{array}$ & 500 & Contact \\
\hline Japanese cedar & 4950 & $\begin{array}{l}2150^{\mathrm{c}} \\
1610^{\mathrm{d}}\end{array}$ & $\begin{array}{l}2.3 \\
3.1\end{array}$ & 2500 & Contact \\
\hline
\end{tabular}

${ }^{\mathrm{a}}$ Measurement by Hasegawa et al. [2], ${ }^{\mathrm{b}}$ Measurement by Mishiro [14], ${ }^{\mathrm{c}}$ Velocity in the radial direction, ${ }^{\mathrm{d}}$ Velocity in the tangential direction.

the pith. On the other hands, the maximum values show $4414 \mathrm{~m} / \mathrm{s}, 3816 \mathrm{~m} / \mathrm{s}$, and $3796 \mathrm{~m} / \mathrm{s}$, respectively. Their values existed in the outside point of measurement area. In general, the tracheid length gradually increases toward the outside and attains a constant value. An ultrasonic wave dissipates acoustical energy when it occurs at the end of a fiber [10]. Hasegawa et al. demonstrated that $V_{L}$ for Japanese cedar and Japanese cypress were significantly related to the tracheid length [2]. Tracheid length seems to affect $V_{L}$. On the other hand, the average values of velocity in the lateral direction $\left(V_{R T}\right)$ were $1412 \mathrm{~m} / \mathrm{s}, 1606 \mathrm{~m} / \mathrm{s}, 1331 \mathrm{~m} / \mathrm{s}$, respectively. The ratios of $V_{L}$ to $V_{R T}$ ranged from 2.2 to 2.8. Distinct relationship among measurement points such as the axial directions was not observed. As shown in Figure 2, the growth ring structure significantly influences the wave propagation. In the center of the test specimens, the propagation path coincides with the radial direction. However, at the edge of 


\begin{tabular}{|l|l|l|}
\hline 1 & 2 & 3 \\
\hline 4 & 5 & 6 \\
\hline 7 & 8 & 9 \\
\hline
\end{tabular}

(a) Measurement postions

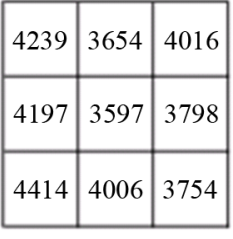

S1

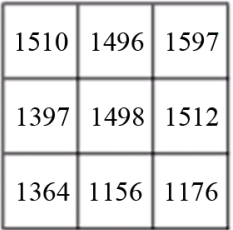

S1

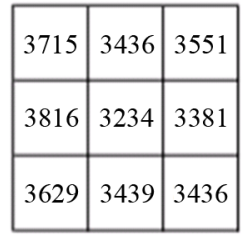

$\mathrm{S} 2$

(b) Axial direction

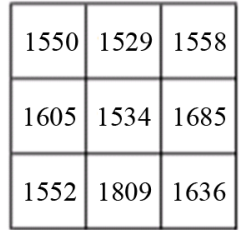

S2

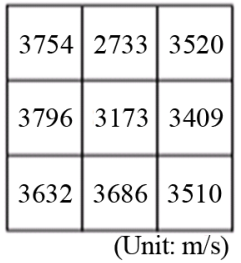

S3

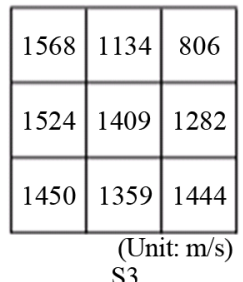

S3

(c) Lateral direction

Figure 5. Distributions of ultrasonic wave velocity in the axial and lateral directions of wood specimens.

the test specimens, the propagation path coincides with the radial and tangential directions. As a result, the ultrasonic beam is deflected and shifted laterally with respect to the incident angle [11]. In addition, for the measurement of $V_{R T}$, the distance between the test specimen and sensor was within the near field distance. As a result, there is a large variation of $V_{R T}$ in wood. In the future, we will determine the optimal measurement condition such as near-field distance for Japanese cedar column.

As shown in Table 2, the velocities obtained using the contact method $\left(V_{c}\right)$ were larger than those obtained using the non-contact method $(V)$ at a significant level of $5 \%$. The correlation coefficients in the axial and lateral directions were 0.48 and 0.40 , respectively. The ratios of $V_{L}$ to $V_{R T}$ ranged from 2.4 to 2.5. The ratios of velocity obtained using the contact method were similar to those obtained using the non-contact method. Vun et al. demonstrated that the velocities measured using the non-contact method showed higher values than those measured using the contact method for an oriented strand board [12]. Raffaella et al. reported that the non-contact ultrasonic velocity of food items was significantly higher than the velocity measured using the contact method (P $<0.05$ ) [13]. Results in this study were not in agreement with those in the previous study [12] [13]. Further research is needed to clarify the reason $V_{c}$ shows larger values than $V$.

The values of velocity in this study were smaller than those in the previous study, which used a contact method, as shown in Table 2. An ultrasonic wave velocity changes with the specimen dimensions and natural frequency [10]. Bucur demonstrated that the ratios of $V_{L}$ to $V_{R}$ in European wood species ranged from 2.4 to 3.4 for softwood [10]. For Japanese cedar, Hasegawa et al. [2] and Mishiro [14] reported that the ratios of velocity in the longitudinal direction to that in the radial direction were 2.3; the ratios of velocity in the longitudinal direction to that in the tangential direction were 3.1. The ratios for a non-contact method were almost the same as those for a contact method. The findings in this study suggest that the ultrasonic wave velocities in Japanese cedar could be measured with a non-contact method by using air-coupled ultrasonics.

\section{Conclusion}

Ultrasonic wave velocities in the axial and lateral directions on Japanese cedar columns can be measured with a 
non-contact method by using air-coupled ultrasonics. As compared, the velocities were also measured by using the contact method. The velocities in the non-contact method were smaller than those measured using the contact method. The ratios of velocity were the same as those in a contact method. These results in the present study have suggested that the air-coupled ultrasonic wave is a useful tool for non-contact and nondestructive evaluation in Japanese cedar. Most importantly, this study could be considered as the first step toward the application of air-coupled ultrasonics to the nondestructive evaluation in Japanese cedar columns. In the future, the need is envisaged to measure an ultrasonic velocity in a full-sized lumber and to explore the possibility of non-contact and nondestructive evaluation in existing wood constructions using air-coupled ultrasonics.

\section{Acknowledgements}

This work was supported by Grant-in-Aid for Challenging Exploratory Research (No. 23658147) from Japan Society for the Promotion of Science and TOSTEM Foundation for Construction Materials Industry Promotion. The publication was supported in part by the Research Grant for Young Investigators of Faculty of Agriculture, Kyushu University.

\section{References}

[1] Forestry Agency (2013) Annual Report on Trends in Forests and Forestry. Forestry Agency, Tokyo (in Japanese).

[2] Hasegawa, M., Takata, M., Matsumura, J. amd Oda, K. (2011) Effect of Wood Properties on Within-Tree Variation in Ultrasonic Wave Velocity in Softwood. Ultrasonics, 51, 296-302. http://dx.doi.org/10.1016/j.ultras.2010.10.001

[3] Mori, T., Yanase, Y., Tanaka, K., Kawano, K., Noda, Y., Mori, M., Kurisaki, H. and Komatsu, K. (2013) Evaluation of Compressive and Bending Strength Properties of Wood Damaged from Bio-Deterioration. Zairyo, 62, $280-285$ (in Japanese with English Abstract). http://dx.doi.org/10.2472/jsms.62.280

[4] Hasegawa, M., Yano, Y., Matsumura, J. and Oda, K. (2012) Prospects for Within-Tree Variation of the Acoustoelastic Behaviors in Japanese Cedar. NDT and E International, 49, 57-63. http://dx.doi.org/10.1016/j.ndteint.2012.03.010

[5] Vun, R.Y., Hoover, K., Janowiak, J. and Bhardwaj, M. (2008) Calibration of Non-Contact Ultrasound as an On-Line Sensor for Wood Characterization: Effects of Temperature, Moisture and Scanning Direction. Applied Physics A: Materials Science \& Processing, 90, 191-196. http://dx.doi.org/10.1007/s00339-007-4256-6

[6] Dahmena, S., Ketatab, H.M., Hédi, B.G. and Hosten, B. (2010) Elastic Constants Measurement of Anisotropic Olivier Wood Plates Using Air-Coupled Transducers Generated Lamb Wave and Ultrasonic Bulk Wave. Ultrasonics, 50, 502-507. http://dx.doi.org/10.1016/j.ultras.2009.10.014

[7] Hsu, D.K., Utrata, D. and Kuo, M. (2010) NDE of Lumber and Natural Fiber Based Products with Air-Coupled Ultrasound. Review of Progress in Quantitative Nondestructive Evaluation, 29, 1533-1540.

[8] Sanabria, S.J., Furrer, R., Neuenschwander, J., Niemz, P. and Sennhauser, U. (2011) Air-Coupled Ultrasound Inspection of Glued Laminated Timber. Holzforschung, 65, 377-387. http://dx.doi.org/10.1515/hf.2011.050

[9] Sanabria, S.J., Furrer, R., Neuenschwander, J., Niemz, P. and Sennhauser, U. (2013) Novel Slanted Incidence AirCoupled Ultrasound Method for Delamination Assessment in Individual Bonding Planes of Structural Multi-Layered Glued Timber Laminates. Ultrasonics, 53, 1309-1324. http://dx.doi.org/10.1016/j.ultras.2013.03.017

[10] Bucur, V. (2006) Acoustics of Wood. 2nd Edition, Springer-Verlag, Berlin.

[11] Sanabria, S.J., Furrer, R., Neuenschwande, J., Niemz, P. and Schütz, P. (2015) Analytical Modeling, Finite-Difference Simulation and Experimental Validation of Air-Coupled Ultrasound Beam Refraction and Damping through Timber Laminates, with Application to Non-Destructive Testing. Ultrasonics, 63, 65-85. http://dx.doi.org/10.1016/j.ultras.2015.06.013

[12] Vun, R.Y., Wu, Q., Bhardwaj, M.C. and Sted, G. (2003) Ultrasonic Characterization of Structural Properties of Oriented Strandboard: A Comparison of Direct-Contact and Non-Contact Methods. Wood and Fiber Science, 35, 381396.

[13] Raffaella, S. and John, N.C. (2001) Non-Contact Ultrasonic Measurements in Food Materials. Food Research International, 34, 865-870. http://dx.doi.org/10.1016/S0963-9969(01)00110-7

[14] Mishiro, A. (1996) Effect of Density on Ultrasonic Velocity in Wood. Mokuzai Gakkaishi, 42, 887-894. 